ACCEPTED MANUSCRIPT

\title{
Al-based MOF derived self-assembled carbon nanosheets as innovative anodes for Li- and Na-ion batteries
}

To cite this article before publication: XieRong Zeng et al 2019 Nanotechnology in press https://doi.org/10.1088/1361-6528/ab647b

\author{
Manuscript version: Accepted Manuscript \\ Accepted Manuscript is "the version of the article accepted for publication including all changes made as a result of the peer review process, \\ and which may also include the addition to the article by IOP Publishing of a header, an article ID, a cover sheet and/or an 'Accepted \\ Manuscript' watermark, but excluding any other editing, typesetting or other changes made by IOP Publishing and/or its licensors" \\ This Accepted Manuscript is @ 2019 IOP Publishing Ltd.
}

During the embargo period (the 12 month period from the publication of the Version of Record of this article), the Accepted Manuscript is fully protected by copyright and cannot be reused or reposted elsewhere.

As the Version of Record of this article is going to be / has been published on a subscription basis, this Accepted Manuscript is available for reuse under a CC BY-NC-ND 3.0 licence after the 12 month embargo period.

After the embargo period, everyone is permitted to use copy and redistribute this article for non-commercial purposes only, provided that they adhere to all the terms of the licence https://creativecommons.org/licences/by-nc-nd/3.0

Although reasonable endeavours have been taken to obtain all necessary permissions from third parties to include their copyrighted content within this article, their full citation and copyright line may not be present in this Accepted Manuscript version. Before using any content from this article, please refer to the Version of Record on IOPscience once published for full citation and copyright details, as permissions will likely be required. All third party content is fully copyright protected, unless specifically stated otherwise in the figure caption in the Version of Record.

View the article online for updates and enhancements. 
a. Shenzhen Key Laboratory of Special Functional Materials \& Shenzhen Engineering Laboratory for Advance Technology of Ceramics, College of Materials Science and Engineering, Shenzhen University, Shenzhen 518060, PR China.

b. State Key Laboratory of Solidification Processing, Carbon/Carbon Composites Research Center, Northwestern Polytechnical University, Xi'an 710072, PR China.

c. School of Chemistry, University College Cork and Tyndall National Institute, Cork, T12YN60, Ireland.

d. School of Aerospace, Transport and Manufacturing, Cranfield University, Cranfield, Bedfordshire, MK43 OAL, $U K$.

* Correspondence:zoujizhao@szu.edu.cn (J Z.Zou); zengxier@szu.edu.cn (X R.Zeng)

Keywords: Porous carbon nanosheets, nanostructure, 2D-MOF, Li-ion, Na-ion

\begin{abstract}
Functional modification and structural design of carbon electrode materials are considered as a cost-effective method to improve their electrochemical performance. In this study, a solvothermal method is applied to realize self-assembly of the metal-organic framework. After simple carbonization and acid treatment, carbon nanosheets with 2D adjustable defective sub-units are successfully prepared for the first time. It is found that carbonization temperature has a significant effect on the carbon skeleton structure. The optimal nanostructures with large specific surface area
\end{abstract}


and appropriate pore size distribution make self-assembled carbon nanosheets having excellent $\mathrm{Li} / \mathrm{Na}$ - ion storage properties. In addition, the adjustable carbon skeleton structure can effectively avoid irreversible damage when charge-discharge cycles. For Li-ion batteries, a specific capacity of $825 \mathrm{mAh} \mathrm{g}^{-1}$ is achieved after 100 cycles at $100 \mathrm{~mA} \cdot \mathrm{g}^{-1}$, while for Na-ion batteries a specific capacity of $193 \mathrm{mAh} \mathrm{g}^{-1}$ is observed after 100 cycles at $100 \mathrm{~mA} \cdot \mathrm{g}^{-1}$. Moreover, for Na-ion batteries, even at a high rate of $1000 \mathrm{~mA} \cdot \mathrm{g}^{-1}$ the material delivers a specific capacity of $109.5 \mathrm{mAh} \mathrm{g}^{-1}$ after 3500 cycles.

\section{Introduction}

The technological revolution of mobile communication and electric locomotive is urgently needed to develop high performance energy storage equipment. The next-generation battery system is required to have features such as long cycle stability, high energy storage and fast charging-discharging. In order to realize the above assumption, lithium ion batteries (LIBs) have been widely studied and commercialized in the past few decades. ${ }^{[1-5]}$ Sodium ion batteries (SIBs) have similar electrochemical mechanisms to the LIBs. Meanwhile, sodium metal can be easily extracted from sodium chloride, therefore, SIBs are regarded as a potential candidate to replace the LIBs. ${ }^{[1-5]}$ Based on the advantages such as non-toxic, abundant resources and tailor-able nanostructure, the carbon materials with special structures and ultra-large interlayer spacing have been widely reported in the field of LIBs and SIBs. ${ }^{[1-7]}$

As a representative, metal organic framework (MOF)-derived carbon materials have designable pore structures and large specific surface area. Importantly, the heteroatom-doped carbon can be easily obtained by carbonizing MOF materials. ${ }^{[3,8,9]}$ Recently, super-carbon structures derived from the MOFs with well-designed porous channels and novel morphologies were reported. ${ }^{[3,6,9,10,11]}$ These innovative nanostructures avoid damage on the electrode materials caused by volume expansion, and the interconnected structural-networks are favorable for charge-transfer, therefore, 
the carbon-coated anode exhibiting an excellent rate performance with high-rate cycling stability. However, the formation of these electrodes is often associated with addition of templates ${ }^{[3,9,10,11,12]}$ or activation processes, ${ }^{[6]}$ which usually causes environmental pollution and increases the cost of preparation.

In this study, we use the self-assembled MOFs as both template and carbon source to synthesize carbon nanosheets with 2D sub-units. The prepared carbon nanosheets can obtain large specific surface area and hierarchical porous structure. Furthermore, the physical-chemical parameters of the carbon nanosheets can be effectively controlled by adjusting the carbonization temperature. In order to explore the relationship between carbon structure and $\mathrm{Li} / \mathrm{Na}$-ion storage capacity, the electrochemical properties of carbon nanostructures prepared at different temperatures were systematically studied.

\section{Experimental details}

\subsection{Sample preparation}

The synthesis of SAM: 4,4'-biphenyldicarboxylic acid $(0.130842 \mathrm{~g})$ and $\mathrm{Al}\left(\mathrm{NO}_{3}\right)_{3} .9 \mathrm{H}_{2} \mathrm{O}$ (0.2828 g) were added to a $20 \mathrm{~mL}$ of $\mathrm{N}, \mathrm{N}$-dimehylformamide (DMF). After continuous stirring for 20 minutes, the mixture was transferred to a $50 \mathrm{~mL}$ Teflon-lined autoclave, which was further autoclaved at $120{ }^{\circ} \mathrm{C}$ for $24 \mathrm{~h}$. After centrifugation, the product was washed with ethanol for three times and dried at $80{ }^{\circ} \mathrm{C}$, and finally the self-assembled Al-MOF (SAM) was obtained. In order to highlight the superiority of our synthetic conditions, the $\mathrm{Al}-\mathrm{MOF}$ synthesized at $180^{\circ} \mathrm{C}$ was also prepared. Typically, the drug was added according to the ratio of $\mathrm{Al}\left(\mathrm{NO}_{3}\right)_{3} .9 \mathrm{H}_{2} \mathrm{O}(1.88 \mathrm{~g})$ : 4,4'-biphenyldicarboxylic acid $(0.8 \mathrm{~g})$ : DMF $(60 \mathrm{~mL}) .{ }^{[13,14]}$ The mixed solution was heated at $180^{\circ} \mathrm{C}$ for $24 \mathrm{~h}$, and the obtained sample was then marked as Al-MOF $\left(180^{\circ} \mathrm{C}\right)$.

To get carbon nanosheets, the SAM were annealed at $600,700,800$, and $1000{ }^{\circ} \mathrm{C}$ for $1 \mathrm{~h}$ in argon atmosphere with a heating rate of $5{ }^{\circ} \mathrm{C} \mathrm{min}^{-1}$, respectively. In order to remove aluminum 
element, the carbonization products of the SAM was immersed in $\mathrm{HCl}(10 \%)$ via a hydrothermal reaction at $80{ }^{\circ} \mathrm{C}$ for 2 days. According to different calcination temperatures, the obtained carbon nanosheets were named as PCNS-n ( $n=600,700,800$ and 1000). The carbonization temperature of Al-MOF $\left(180^{\circ} \mathrm{C}\right)$ was set to $700^{\circ} \mathrm{C}$, and other carbonization parameters were kept same as the SAM.

\subsection{Characterizations}

The Powder X-ray diffraction (XRD) patterns of the PCNS-n were recorded in a focused optical path mode of Rigaku SmartLab X-ray Diffractometer, and the data were collected from $2 \theta=15^{\circ}$ to $80^{\circ}$ for the PCNS-n and $5^{\circ}$ to $60^{\circ}$ for the precursor, respectively. Discovery TGA 55 thermal gravimetric analyzer was used to obtain the thermo-gravimetric analysis (TGA) curves under $\mathrm{N}_{2}$ atmosphere. The ASAP 2020 HD88 system (Micromeritics Company, USA) was used to acquire the specific surface area and the pore size distribution of the PCNS-n. The confocal Raman spectra of the PCNS-n were acquired using a Renishaw inVia Raman Microscope (UK, Renishaw Company). The scanning electron microscopy (SEM) images were collected using a field emission electron microscope (Japan, SU-70, Hitachi). The transmission electron microscope (TEM) images were collected using Japan Electron Optics Laboratory (JEOL) JEM2010. A high-resolution auger electron spectrometer (MICROLAB 350) was applied to measure X-ray photoelectron spectroscopy (XPS), and elemental analysis using Elementar Vario EL CUBE (Germany).

\subsection{Cell fabrication and measurements}

In this study, all batteries were prepared in MBRAUN MB-Labstar 1500/780 glove box $\left(\mathrm{O}_{2}<0.1\right.$ ppm, $\left.\mathrm{H}_{2} \mathrm{O}<0.1 \mathrm{ppm}\right)$. The batteries were assembled by CR2032-type coin-cells. The slurry of the working electrode consists of three parts: active materials (80\%), acetylene black (10\%) and PVDF (10\%). The obtained slurry was blade casted onto a copper foil, and then dried at $70{ }^{\circ} \mathrm{C}$ for $900 \mathrm{~min}$ under vacuum $(-0.1 \mathrm{mmHg})$. The areal loading of active substrate was about $1.5 \mathrm{mg} \mathrm{cm}^{-2}$. Different electrolytes and diaphragm materials were used in the assembly process. For LIBs, a mixture of 
ethylene carbonate (EC) and dimethyl carbonate $(\mathrm{DMC})($ volume ratio=1) with added $1 \mathrm{M} \mathrm{LiPF} 6$ was used as an electrolyte. The Celgard 2300 was served as the separator materials. For $\mathrm{SIBs} \mathrm{NaClO}_{4}(1$ M) in propylene carbonate was used as the electrolyte. The GF/D glass fiber was used as the separator. In order to test the Li/Na ion storage mechanism of the PCNS-n, cyclic voltammetry $(\mathrm{CV})$ measurements were carried out using a Solartron Analytical 1400 cell test system $\left(0.1 \mathrm{mV} \mathrm{s}^{-1}\right)$. The charge-discharge performance was tested using a NEWARE BTS-4008 system. Electrochemical impedance spectroscopy (EIS) data was obtained through Solartron analytical 1400 cell test system.

\section{Results and discussion}

\subsection{Characterization of PCNS}

The SAM and the Al-MOF $\left(180^{\circ} \mathrm{C}\right)$ were successfully prepared through a simple hydrothermal synthesis process. As shown in Fig.1. (a-c) and Figure.S1, the FESEM images of the SAM display a small nanoparticle-assembled flake-like morphology, and the average diameter of the SAM is about $300 \mathrm{~nm}$ (Fig.1.(c)). The Al-MOF $\left(180^{\circ} \mathrm{C}\right)$ displays a three-dimensional structure that is stacked by two-dimensional lamellar structure. In order to further determine the phase composition of the SAM and $\mathrm{Al}-\mathrm{MOF}\left(180^{\circ} \mathrm{C}\right)$, the X-ray diffraction measurements (XRD) were carried out. Although the reactions were carried out at different reaction conditions, the peak positions of the SAM and $\mathrm{Al}-\mathrm{MOF}\left(180^{\circ} \mathrm{C}\right)$ are the same, and the phase composition of the SAM and the Al-MOF $\left(180^{\circ} \mathrm{C}\right)$ are in consistent well with the calculated XRD patterns of the Al-MOF. ${ }^{[11]}$ However, it is worth noting that a broadening phenomenon of the characteristic peak were observed in Fig.1(e) and Figure.S2, and this phenomenon is possibly due to the smaller crystal size of the Al-MOF, ${ }^{[15-17]}$ which futher lead to the formation of the characteristic Al-MOF with an interlaced overlap peak. 

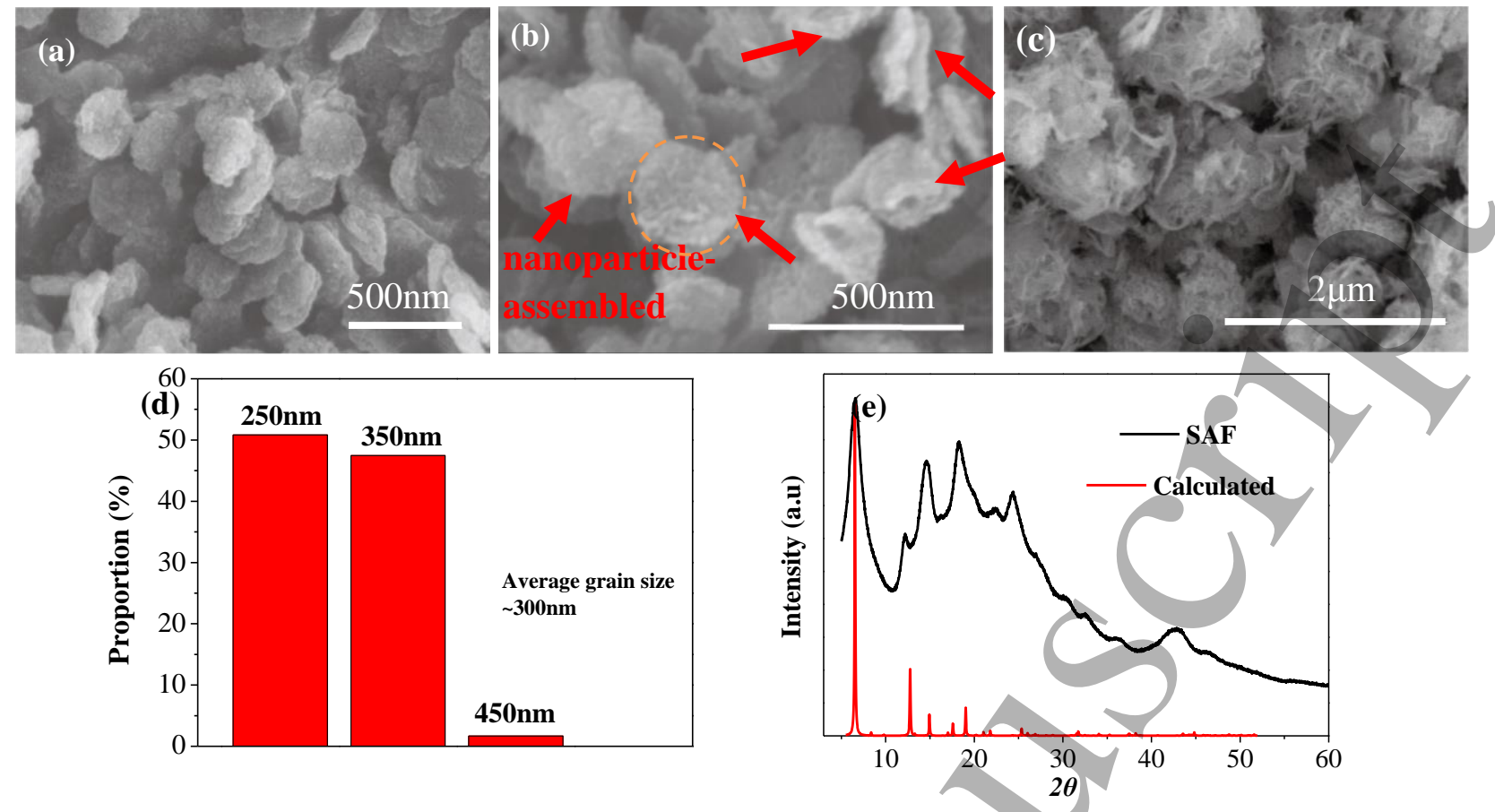

Fig.1. (a,b) SEM images of the SAM and (c) Al-MOF $\left(\mathbf{1 8 0}^{\circ} \mathrm{C}\right)$; (d) The particle-size distribution of the SAM; (e) X-ray diffraction patterns of calculated the Al-MOF and SAM.

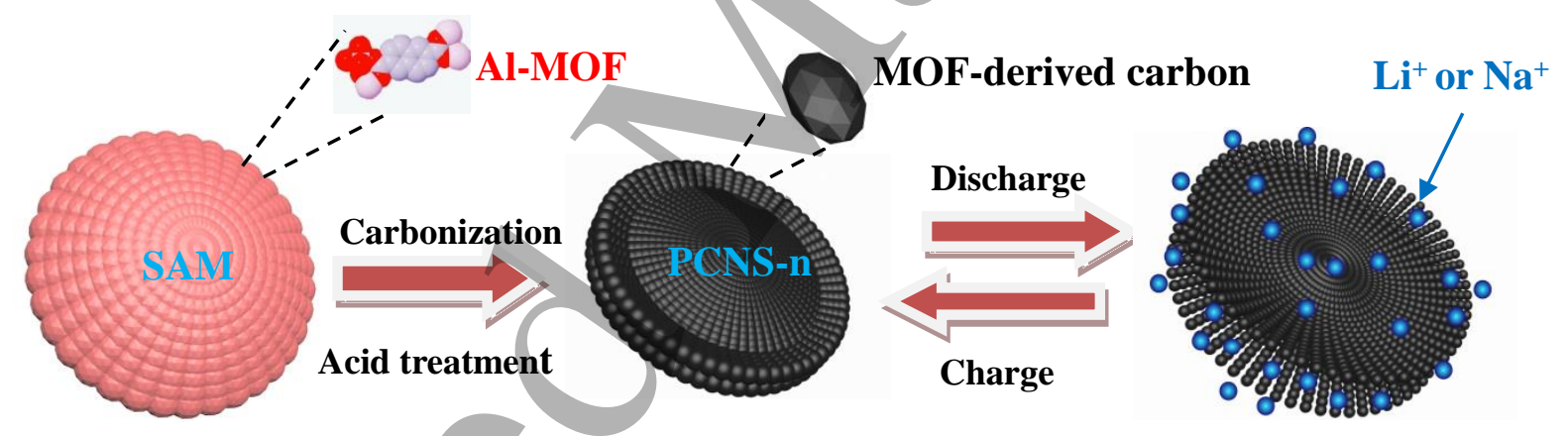

Scheme 1. Preparation process of the PCNS-n and charge -discharge processes.

As illustrated in Scheme 1, the PCNS-n was successfully prepared through a single-step carbonization followed by acid treatment. The morphology and microstructure of the PCNS-n were examined by FESEM and TEM Fig.2(a-c). It was found that the PCNS can maintain the layer alignment to their parent with orderly arrangements in the temperature range of $600-800{ }^{\circ} \mathrm{C}$. However, as the temperature further rises to $1000{ }^{\circ} \mathrm{C}$, a large number of cracks/voids were formed after the calcination followed by acid treatment, and this phenomenon is likely caused by the decomposition of the ligand molecules, ${ }^{[18-20]}$ which was further confirmed by TGA analysis. Compared to the SAM, a weight loss of $\sim 68$ wt $\%$ was confirmed when the temperature increases 
from room temperature to $800^{\circ} \mathrm{C}$ (Figure.S3).

TEM technique was employed to characterize the detailed microstructure of the PCNS-700. Low-resolution transmission electron microscopy (LR-TEM) shows that the ultra-thin carbon structure has an non-uniform surface with tightly interconnected lamellar particles (Fig.3 (a,b)), which was further observed by a high-resolution transmission electron microscopy (HR-TEM). A circular-like building block material with hierarchical porous structure was observed, and that sub-unit structure was derived from the pyrolysis of small nanoparticle-assembled Al-MOF. Simultaneously, no obvious graphitization fringes were observed in Fig. 3(c,d). This phenomenon further proves that the PCNS-n material mainly presents an amorphous carbon structure, which is similar to $\mathrm{Al}-\mathrm{MOF}\left(180^{\circ} \mathrm{C}\right)$-derived carbon materials (Figure.S4).

Fig.4 (a) shows XRD patterns of the PCNS-n. The characteristic peaks of $\gamma-\mathrm{Al}_{2} \mathrm{O}_{3}$ were not observed (JCPDS NO.10-425) (Figure.S5), instead two broad diffraction peaks at around $2 \theta=25^{\circ}$ and $43^{\circ}$ were observed in the XRD patterns, which corresponds to the $\left(\begin{array}{lll}0 & 0 & 2\end{array}\right)$ and $\left(\begin{array}{lll}1 & 0 & 0\end{array}\right)$ planes of amorphous carbon, respectively. The contents of carbon, hydrogen, nitrogen and sulfur in the PCNS-n were confirmed by elemental analysis. It is shown that the main component of the PCNS-n is carbon. With the increase of carbonization temperature, the carbon content increases gradually in the PCNS-n (Table.1), and the similar phenomena have been observed in the carbonization processes of other Al-based MOF. ${ }^{[21]}$ This phenomenon may be caused by more carbon basal planes that are formed by the decomposition of the organic components . ${ }^{[22]}$

In order to further analyze the thermogravimetric process of the SAM, the thermo-gravimetric analysis (TGA) was employed. As shown in Figure.S3, when the temperature rises to $350{ }^{\circ} \mathrm{C}$, there is about $19.1 \%$ weightlessness, which corresponds to the removal of water and solvent molecules in the SAM. A rapid thermal weightlessness process was observed during the stabilization and carbonization stages $\left(450-600^{\circ} \mathrm{C}\right)$, and this process corresponds to the swelling of matrix, and removal of the guest molecules. Additionally, compared with the Al-MOF $\left(180^{\circ} \mathrm{C}\right)$-derived carbon materials, ${ }^{[13,14]}$ the carbonized product of the SAM has a higher carbon content (Table.S1 and Table.1), and this result suggests that the synthesis conditions also have a significant effects on the 
carbon content in the Al-based MOF derived carbon materials. The sample synthesized under $180{ }^{\circ} \mathrm{C}$ only exhibits a lower carbon content (58.2\%), which is not benefited for improving the conductivity of carbon electrode materials. ${ }^{[23]}$

Table.1. The elemental analysis results of the PCNS-n

\begin{tabular}{lllll}
\hline samples & \multicolumn{4}{c}{$\mathrm{N}[\mathrm{wt} \%] \mathrm{C}[\mathrm{wt} \%] \mathrm{H}[\mathrm{wt} \%] \mathrm{S}[\mathrm{wt} \%]$} \\
\hline PCNS-600 & 0.14 & 81.71 & 1.918 & 0.133 \\
PCNS-700 & 0 & 88.20 & 1.799 & 0.669 \\
PCNS-800 & 0 & 89.15 & 1.540 & 0.102 \\
PCNS-1000 & 0 & 90.85 & 1.656 & 0.121 \\
\hline
\end{tabular}

The Raman spectrum of the PCNS-n shows two carbon characteristic peaks at $1350 \mathrm{~cm}^{-1}$ and $1586 \mathrm{~cm}^{-1}$, which corresponds to D and G bands, respectively. The intensity ratio of the G band to D band $\left(\mathrm{I}_{\mathrm{D}} / \mathrm{I}_{\mathrm{G}}\right)$ is generally employed to evaluate the extent of structural disorder for the carbon materials. ${ }^{[24]}$ With the increase of carbonization temperature, an increasing trend in the $\mathrm{I}_{\mathrm{D}} / \mathrm{I}_{\mathrm{G}}$ ratio was observed. It was estimated that the intensity ratios $\left(\mathrm{I}_{\mathrm{D}} / \mathrm{I}_{\mathrm{G}}\right)$ for PCNS-600, PCNS-700, PCNS-800, and PCNS-1000 were 0.7568, 0.831, 0.991 and 1.047, respectively. The skeleton structure of the PCNS-1000 has the highest $\mathrm{I}_{\mathrm{D}} / \mathrm{I}_{\mathrm{G}}$ ratio, indicating that the high-temperature carbonization of the SAM will lead to more defects and disorder in the PCNS framework, and these results were confirmed by SEM analysis. (Fig.2). 

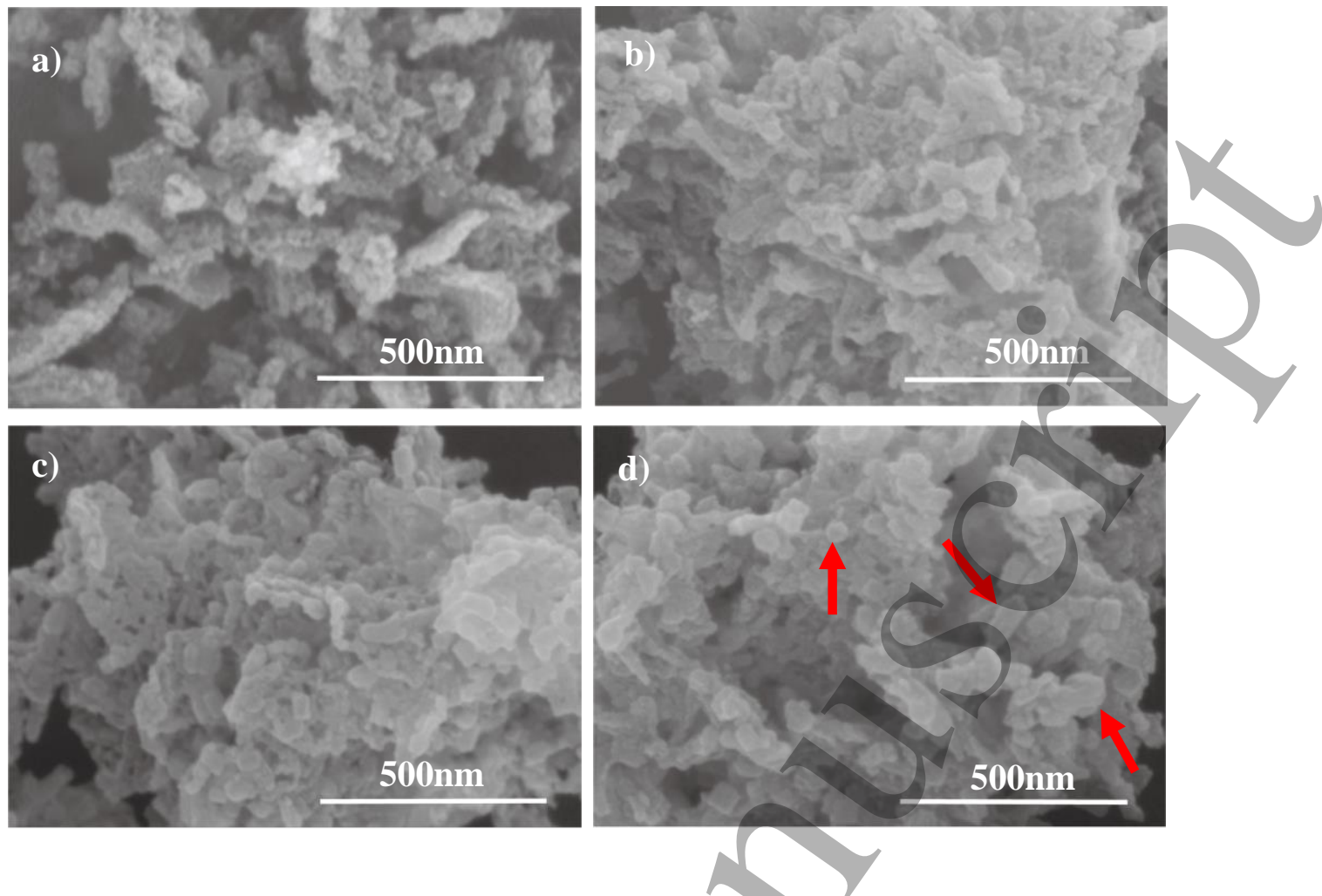

Fig.2. SEM images for the samples annealed at $600^{\circ} \mathrm{C}(\mathrm{a}), 700^{\circ} \mathrm{C}(\mathrm{b}), 800^{\circ} \mathrm{C}(\mathrm{c})$ and $1000^{\circ} \mathrm{C}(\mathrm{d})$.

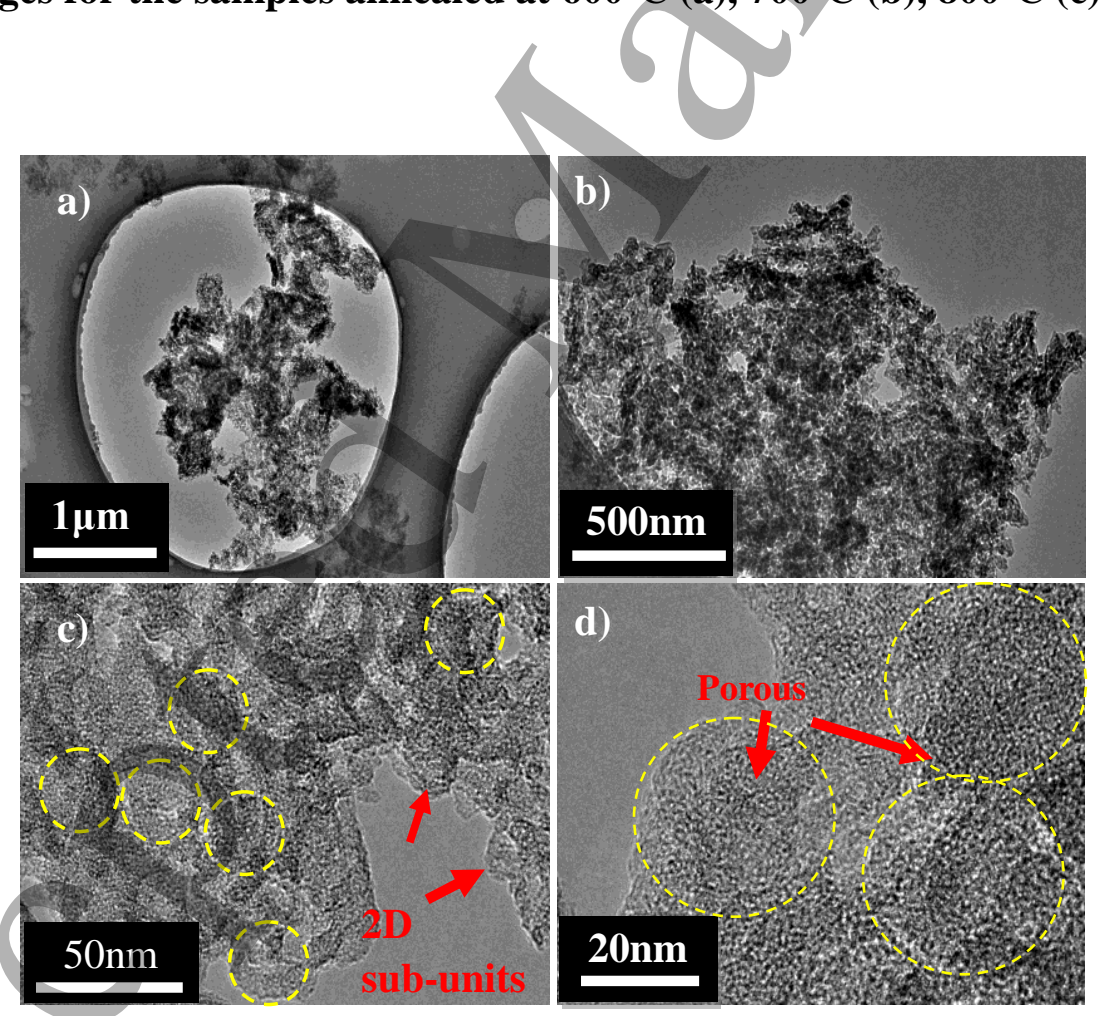

Fig.3. (a,b) Low- and (c,d) high- resolution TEM images of the PCNS-700.

Fig.4.(c) shows the nitrogen adsorption-desorption isotherms of the PCNS-n, and it exhibits type

I/IV characteristics curve, which indicates the existence of micropores and mesopores in the 
PCNS-n, ${ }^{[11]}$ and this conclusion was further confirmed by DFT analysis (Fig.4. (d)). The data of the surface area, total pore volume and average pore size of the PCNS-n are listed in Table.2. Comparing with the PCNS-1000, the other samples have a larger specific surface area and pore volume, which are regarded as an excellent way to ameliorate the electrolyte infiltration and to avoid the volume expansion of electrode materials..$^{[2,5]}$ With the increase of carbonization temperature, the specific surface area and pore volume of the PCNS-1000 decrease obviously. Meanwhile, the width of the average pore size increases sharply, and these variations in structure and behavior could be related to the formation of extended defects in the carbon matrix. This conclusion is in consistent with the observations from the SEM, Raman, and XRD data (Fig.2, Fig.4(a,b)).

\begin{tabular}{llll}
\hline \multicolumn{1}{l}{ Table S2. Textural parameters of the PCNS-n } \\
\hline Sample & $\mathbf{S}_{\text {BET }}$ & $\mathbf{V}_{\text {total }}$ & Average \\
& $\left(\mathbf{m}^{\mathbf{2}} \cdot \mathbf{g}^{-\mathbf{1}}\right)$ & $\left(\mathbf{c m}^{\mathbf{3}} \cdot \mathbf{g}^{-\mathbf{1}}\right)$ & $(\mathbf{n m})$ \\
PCNS-600 & 1321.0 & 1.55 & 4.71 \\
PCNS-700 & 1571.4 & 1.78 & 4.54 \\
PCNS-800 & 1305.6 & 1.53 & 4.69 \\
PCNS-1000 & 465.1 & 0.90 & 7.76 \\
\hline
\end{tabular}

In previous reports, oxygen-rich functional groups on the surface of carbon substrates were thought to benefit the absorption and release of $\mathrm{Li}^{+} / \mathrm{Na}^{+}$ion. ${ }^{[1,25,26]}$ In order further to identify the surface functional groups of the PCNS, X-ray photoelectron spectra (XPS) was carried out. Typically, the characteristic peaks of $\mathrm{C} 1 \mathrm{~s}$ and $\mathrm{O} 1 \mathrm{~s}$ are displayed in Fig.4 (e, f). The peaks of C1s can be further decomposed into three characteristic peaks, corresponding to $\mathrm{C}-\mathrm{C}$ at $284.1 \mathrm{eV}, \mathrm{C}-\mathrm{O}$ at $284.9 \mathrm{eV}$ and 
$\mathrm{C}=\mathrm{O}$ at $285.6 \mathrm{eV}$ (Fig.4(e)). Three small peaks can be obtained by decomposing O1s (Fig.4(f)). The peak at $534 \mathrm{eV}$ is considered to be carboxylic groups, and the peaks located at $532.3 \mathrm{eV}$ and $531 \mathrm{eV}$ correspond to the $\mathrm{C}-\mathrm{O}-\mathrm{C}$ and $\mathrm{C}=\mathrm{O}$, respectively, which agree well with the results from $\mathrm{C} 1 \mathrm{~s}$.
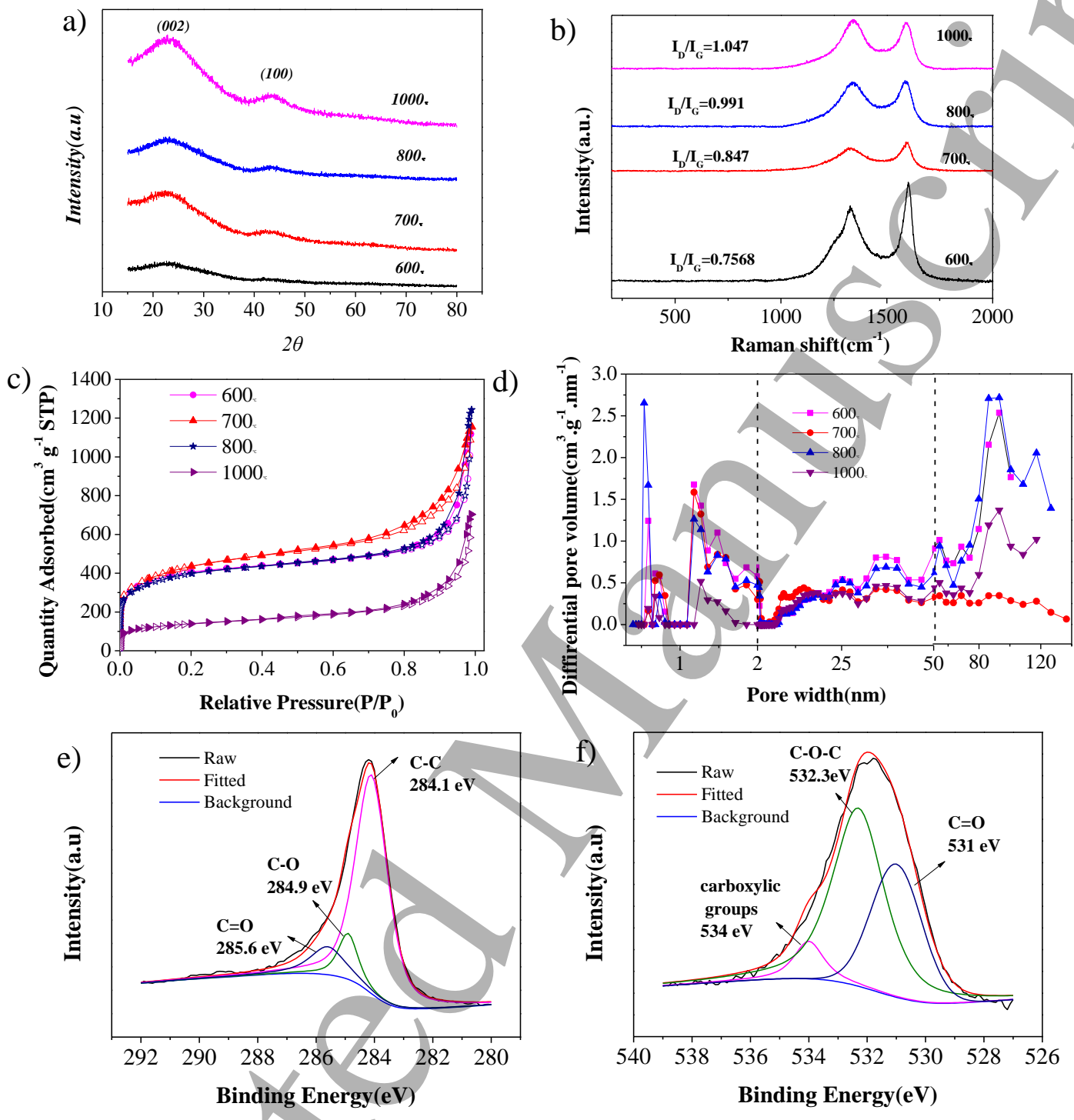

Fig.4. XRD curve (a), Raman spectra (b), N2 adsorption-desorption isotherms (c) and pore size distribution (d), XPS spectrum C1s (e) and O1s (f) of the PCNS-700.

Based on the characterization and analysis of the SAM and their thermal treatment products, formation of the SAM is given in Scheme 1, the small nanoparticles are used as block materials to assemble larger nanostructures. In order to ensure the stable existence of the self-assembled structure, 
the self-assembly process needs to satisfy the minimization of Gibbs free energy. ${ }^{[18]}$ Compared with some other reports, ${ }^{[10,11]}$ the self-assembled SAM does not require templates and structure-directing agents. Besides, it was found that the SAM-derived carbon structures can be effectively controlled through adjusting the carbonization temperature, and this provides favorable conditions for different electrochemical systems. In order to further investigate the relationship between nanostructures and Li/Na-ion storage, the PCNS-n was applied as anode materials for the LIBs and SIBs.

\subsection{Lithium storage performance}

The rate performance of the PCNS-n electrode is shown in Fig.5 (a). The PCNS-700 electrode exhibits an impressive rate capability with average specific capacities of $1126,748,728,702,668$, 489, 246 and $244 \mathrm{mAh} \mathrm{g}^{-1}$ at 100, 200, 500, 1000, 2000, 5000, 10000 and $20000\left(\mathrm{~mA}^{-1} \mathrm{~g}^{-1}\right)$, respectively. In addition, it is worth noting that most of the/specific capacity can be recovered at 100 $\mathrm{mA} \cdot \mathrm{g}^{-1}$ even after rate test. During subsequent cycles, the specific capacity of the PCNS-700 slightly increases, and this phenomenon is fully proved that the PCNS-700 electrode has an excellent reversibility. In sharp contrast to the PCNS-700, the PCNS-1000 exhibits the worst rate performance among all the carbon nanostructures, and this indicates that the carbon nanosheets with over-dispersed 2D sub-units and lower specific surface area might have a negative effect on their $\mathrm{Li} / \mathrm{Na}$-ion storage performance.

The cycling performance of the PCNS-n is shown in Fig.5 (b). The PCNS-700 displays a better cycling ability than the other samples. Besides, it worth noticing that the specific capacities of the PCNS-n exhibit an upward trend, which is resulted from the formation of solid electrolyte inter-phase (SEI) films on the surface of the electrode materials. ${ }^{[12,27,28]}$ After 100 cycles at 100 
$\mathrm{mA} \cdot \mathrm{g}^{-1}$, a relatively high specific capacity of $825 \mathrm{mAh} \cdot \mathrm{g}^{-1}$ was observed, and this value is obviously superior to the previous reports on porous carbon electrodes in related fields. ${ }^{[16,18,29,30]}$

The charge-discharge curves of the PCNS-700 at $100 \mathrm{~mA} \cdot \mathrm{g}^{-1}$ current rate are shown in Fig.5 (c). A large discharge platform with a slope was observed in the first discharge process, the platform is considered to be deintercalation of $\mathrm{Li}^{+}$in the first discharge, while the slope reflects the çapacitance characteristics of the electrode materials. It is noteworthy that a high initial charge capacity of 2048 $\mathrm{mAh} \cdot \mathrm{g}^{-1}$ at $100 \mathrm{~mA} \cdot \mathrm{g}^{-1}$ were observed, and this value is mainly contributed by the physic-sorption and chemisorption of $\mathrm{Li}^{+}$into the porous carbon, and the redox reaction between Li-ion and surface functional groups. ${ }^{[31]}$ Furthermore, it is worth noting that the coulombic efficiency is only about $40 \%$, which is resulted from the irreversibility capacity that caused by a large surface area of the PCNS-700. ${ }^{[31]}$ After two cycles of the charge-discharge curves for the PCNS-700 can be overlapped well, and the coulombic efficiency of $100 \%$ can be achieved, which fully demonstrates the existence of stable SEI films on the electrode surface. ${ }^{[31,32]}$

The $\mathrm{CV}$ measurements were performed over the potential range from $0.01 \mathrm{~V}$ to $3 \mathrm{~V}$ for the LIBs at a scan rate of $0.1 \mathrm{mV} \mathrm{s}^{-1}$. As shown in Fig. 5 (d), during the process of first cathodic scan, the reduction peaks at $0.58 \mathrm{~V}$ and $0.10 \mathrm{~V}$ correspond to the formation of SEI film on the electrode surface and the insertion of Li-ion in carbon materials, respectively. ${ }^{[19,33,34,35]}$ The peak at $\sim 2.43 \mathrm{~V}$ is believed to be caused by the extraction of $\mathrm{Li}^{+}$from porous carbon materials, ${ }^{[1]}$ and these results from $\mathrm{CV}$ analysis are in consistent with the phenomena observed in the charge-discharge curves. 

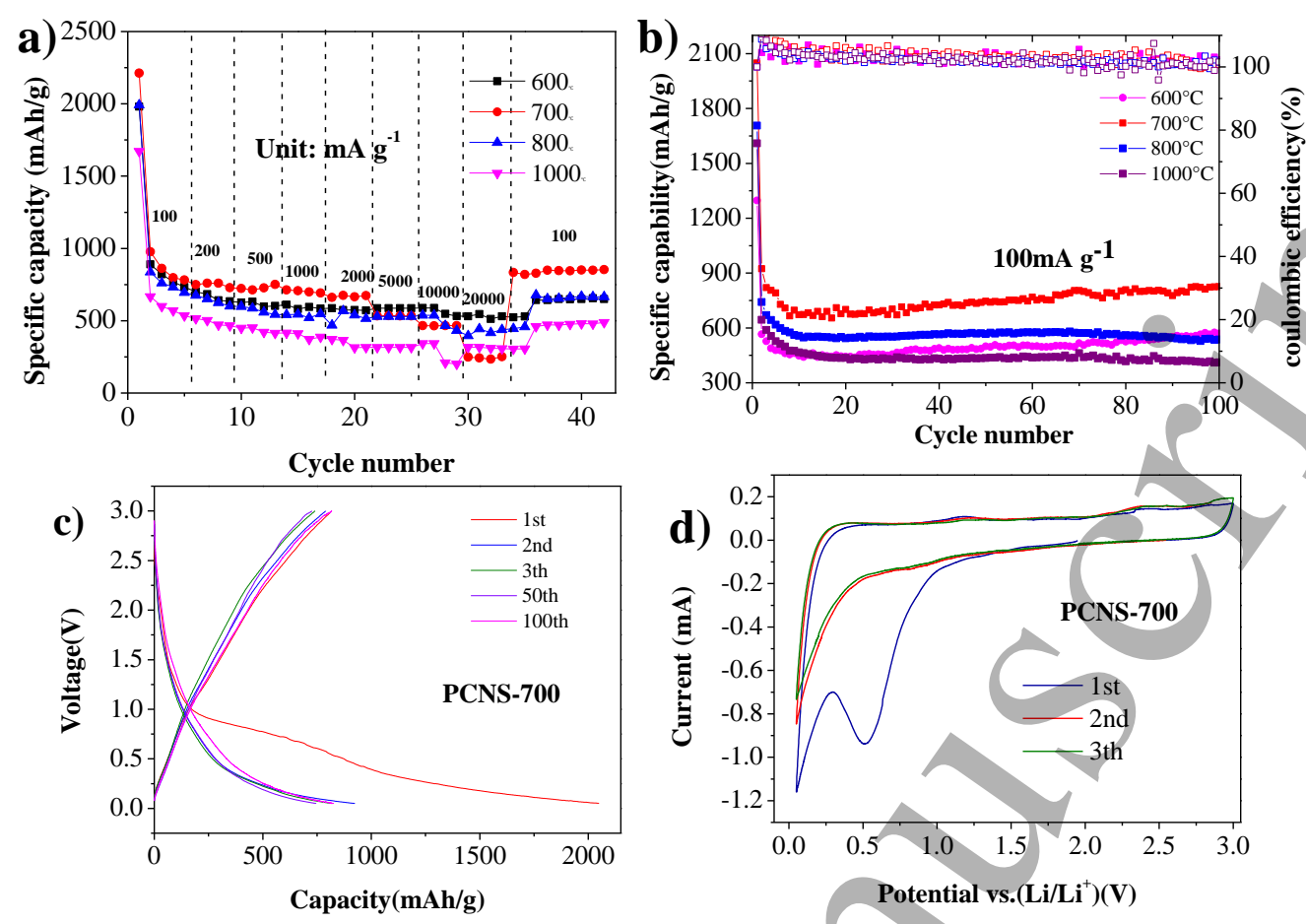

Fig.5 (a) Rate performances of the PCNS, (b) Cycle performance of the PCNS-700 at $100 \mathrm{~mA} \cdot \mathrm{g}^{-1}$ for the Li battery, (c) Charge/discharge curves of the PCNS at $100 \mathrm{~mA} \cdot \mathrm{g}^{-1}$ for the 1st, 2nd, 3rd, 50th and 100th cycles, respectively, and (d) CV curve of the PCNS-700 for Li battery.

\subsection{Sodium storage performance}

The optimized carbon nanosheets exhibit excellent Li-ion storage performance, in order to further test their Na-ion storage performance, the SIBs were assembled by employing the PCNS-n as anode materials. 

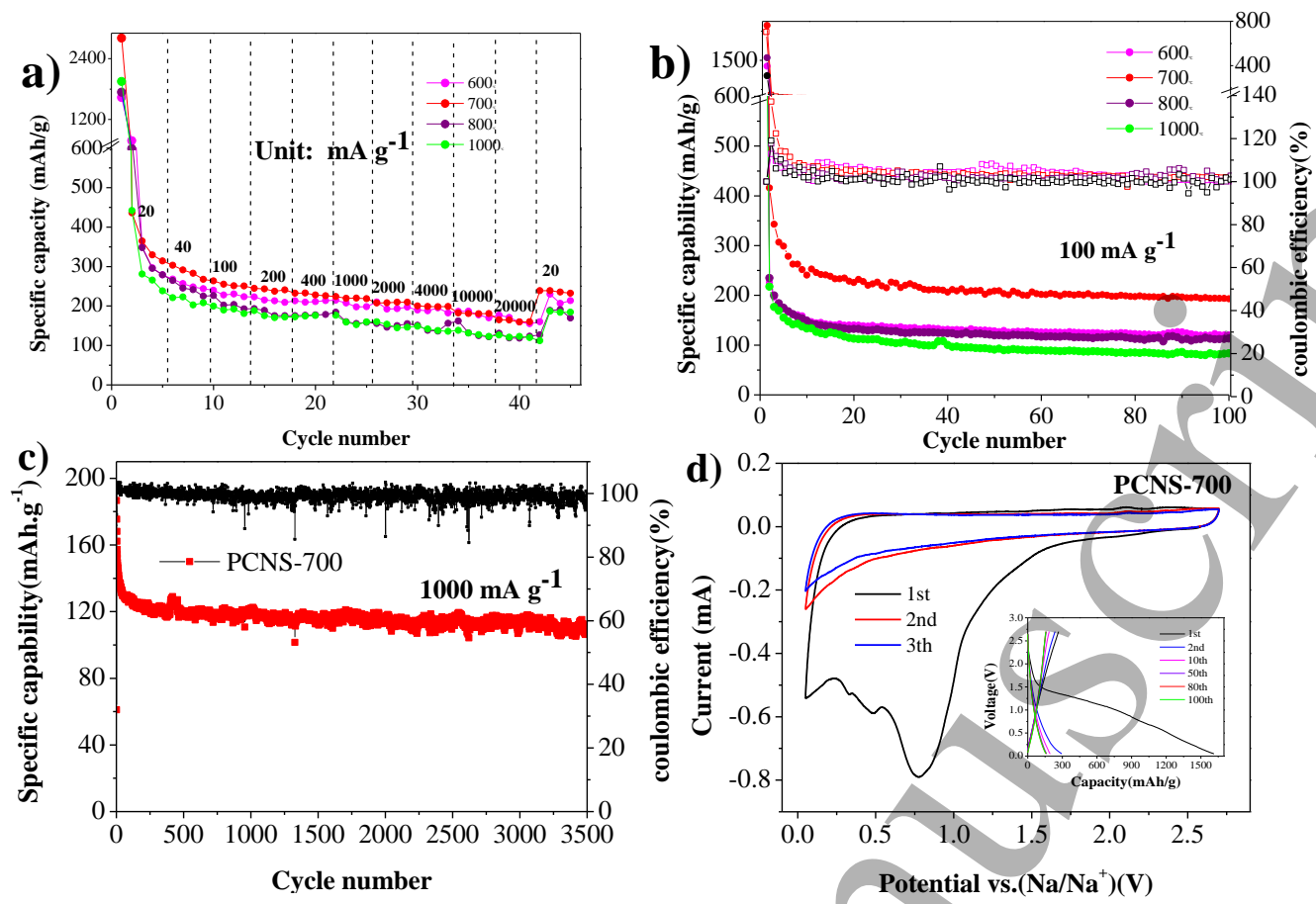

Fig.6 (a) Rate performance of the PCNS-n for Na battery, (b) Cycle performance of the PCNS-n at $100 \mathrm{~mA} \cdot \mathrm{g}^{-1}$, (c) Cycle performance of the PCNS-700 at $1000 \mathrm{~mA} \cdot \mathrm{g}^{-1}$, (d) $\mathrm{CV}$ curves of the PCNS-700 and the inset showing discharge/charge curves of the PCNS-700 at 100 $\mathbf{m A} \cdot \mathrm{g}^{-1}$ for Na battery.

The rate capability of the PCNS-n is shown in Fig.6 (a). To examine the potential of the PCNS-700 as the anode, the cycle performance of the PCNS-700 at different current densities were measured. When it was cycled at 20, 40, 100, 200, 400, 1000, 2000, 4000, 10000 and $20000 \mathrm{~mA} \cdot \mathrm{g}^{-1}$, the corresponding specific capacities were $841,287,257,244.82,244,233,221,212,198,179$ and $161 \mathrm{mAh} \cdot \mathrm{g}^{-1}$, respectively. It is noteworthy that after the rate test, the PCNS-700 electrode can recover most of the specific capacity quickly and run smoothly even at $20 \mathrm{~mA} \cdot \mathrm{g}^{-1}$, and this phenomenon suggests that the PCNS-700 electrode has an excellent rate capability.

The cyclic performance of the PCNS-n at different currents is shown in Fig.6 (b). After 100 cycles at $100 \mathrm{~mA} \cdot \mathrm{g}^{-1}$, a high specific capacity of $193 \mathrm{mAh} \cdot \mathrm{g}^{-1}$ was achieved for the PCNS-700 with 
a coulombic efficiency of $100 \%$. Even after 3500 cycles at $1000 \mathrm{~mA} \cdot \mathrm{g}^{-1}$ (Fig.6 (c)), the SIBs assembled by the PCNS-700 still have a remarkable specific capacity of $109.5 \mathrm{mAh} \cdot \mathrm{g}^{-1}$ /with a coulombic efficiency as high as $100 \%$, indicating the excellent cycle stability of the PCNS-700 electrode.

The charge-discharge curves are shown in the inset of Fig.6 (d). For first galvanostatic discharge-cycle at $100 \mathrm{~mA} \cdot \mathrm{g}^{-1}$, the PCNS-700 displays a large discharge voltage platform, which is mainly due to the formation of SEI film on the surface of the anode material. ${ }^{[5]}$ Cyclic voltammetry (CV) curve was employed to study the mechanism of intercalation and removal of Na-ion in the PCNS-700. As shown in Fig.6 (d), three significant reduction peaks were observed at $0.84 \mathrm{~V}, 0.47 \mathrm{~V}$ and $0.05 \mathrm{~V}$, and those peaks correspond to the reaction of $\mathrm{Na}^{+}$with oxygen-rich functional groups, the formation of SEI film, and insertion of $\mathrm{Na}^{+}$into the carbon layer of the PCNS-700, respectively ${ }^{[1,18,36,37]}$.

During the subsequent cycle, the peak intensity at $0.05 \mathrm{~V}$ become weaken, while the peak at $0.84 \mathrm{~V}$ disappears, and the subsequent $\mathrm{CV}$ curves overlap with each other. This phenomenon correlates to the stable and reversible Na-ion insertion and deinsertion into/from the anode material. ${ }^{[38]}$ In addition, the peak at $2.1 \mathrm{~V}$ was observed during the following cycles, and this process is closely related to Na-ion de-insertion from the PCNS-700. ${ }^{[1]}$

The optimized PCNS-700 electrodes have unique carbon nanostructures, which is an ideal model for studying the storage of $\mathrm{Li} / \mathrm{Na}$-ion in carbon electrodes. As shown in the Scheme 1 , the larger specific surface area of the PCNS-700 ensures that the electrolyte penetrates into the electrode completely. The hierarchical porous structure of the PCNS-700 shortens the diffusion path of solid ions and accelerates the ion-transport. The large pore volume of the PCNS-700 alleviates volume 
expansion and the irreversible damage of electrode can be then effectively suppressed.

\section{Conclusions}

In this study, we designed carbon nanosheets with adjustable defect subunits, and their physical and chemical properties were effectively controlled through adjusting carbonization temperature. The optimized carbon nanostructure can effectively solve the volume expansion problem of the electrode materials. In addition, the hierarchical porous structure of the PCNS-700 provides pore channels for rapid ion-diffusion. When the PCNS-700 is used as an anode material for the SIBs and LIBs, the excellent electrochemical performance was obtained. For LIBs, a specific capacity of 825 $\mathrm{mAh} \mathrm{g}^{-1}$ was achieved after 100 cycles at $100 \mathrm{~mA} \cdot \mathrm{g}^{-1}$, while for $\mathrm{Na}$-ion batteries a specific capacity of $193 \mathrm{mAh} \mathrm{g}^{-1}$ was obtained after 100 cycles at $100 \mathrm{~mA} \cdot \mathrm{g}^{-1}$. Moreover, for Na-ion batteries, even at a high rate of $1000 \mathrm{~mA} \cdot \mathrm{g}^{-1}$, the material delivers a specific capacity of $109.5 \mathrm{mAh} \mathrm{g}^{-1}$ after 3500 cycles. This study opens a new window for controllable synthesis of self-assembled MOF-derived carbon structures, which will provide abundant alternative electrode resources for super-capacitors, Li/Na-ion batteries or lithium sulfur/selenium battery systems, for example.

\section{Acknowledgements}

This work was financially supported by the National Natural Science Foundation of China (Nos. 51202150 and 51272161), Foundation of the State Key Laboratory of Solidification Processing in NWPU(No.SKLSP201110) and Shenzhen Basic Research Program (No. JCYJ20160422091418366).

\section{References}

[1] Shi W P, Zhang Y M, Tian Z Q, Pan Z Y, Key J L and Shen P K 2018 Low temperature synthesis of polyhedral hollow porous carbon with high rate capability and long-term cycling stability as Li-ion and Na-ion battery Journal of Power Sources 398 149-158 
[2] Tian L L, Li S B, Zhang M J, Li S K, Lin L P, Zheng J X, Zhuang Q C, Amine K and Pan F 2016 Cascading Boost Effect on the Capacity of Nitrogen-Doped Graphene Sheets for Li- and Na-Ion Batteries ACS Appl. Mater. Interfaces 8 26722-26729

[3] Zhao R, Liang Z, Zou R and Xu Q 2018 Metal-organic frameworks for batteries Joule 2 2235-2259

[4] Mahadi N B, Park J S, Park J H, Chung K Y, Yi S Y, Sun Y K and Myung S T 2016 Vanadium dioxide-Reduced graphene oxide composite as cathode materials for rechargeable $\mathrm{Li}$ and $\mathrm{Na}$ batteries Journal of Power Sources 326 522-532

[5] Lyu Z Y, Yang L J, Xu D, Zhao J, Lai H W, Jiang Y F, Wu Q, Li Y, Wang X Z and Hu Z 2015 Hierarchical carbon nanocages as high-rate anodes for Li- and Na-ion batteries Nano Res 8 $3535-3543$

[6] Kong L J, Zhu J, Shuang W and Bu X H 2018 Nitrogen-Doped Wrinkled Carbon Foils Derived from MOF Nanosheets for Superior Sodium Storage Adv. Energy Mater 81801515

[7] Wang H G, Wu Z, Meng F L, Ma D L, Huang X L, Wang L M and Zhang X B 2013 Nitrogen-Doped Porous Carbon Nanosheets as Low-Cost, High-Performance Anode Material for Sodium-Ion Batteries ChemSusChem 6 56- 60

[8] Yang J Q, Zhou X L, Wu D H, Zhao X D and Zhou Z 2017 S-Doped N-Rich Carbon Nanosheets with Expanded Interlayer Distance as Anode Materials for Sodium-Ion Batteries Adv. Mater 29 1604108

[9] Kaneti Y V, Tang J, Salunkhe R, Jiang X C, Yu A B, Wu K W and Yamauchi Y 2017 Nanoarchitectured Design of Porous Materials and Nanocomposites from Metal-Organic Frameworks Adv. Mater. 291604898 
[10] Wang D, Zhou W W, Zhang R, Huang X X, Zeng J J, Mao, Y F, Ding C Y, Zhang J, Liu J P and Wen G W 2018 MOF-derived Zn-Mn mixed oxides@carbon hollow disks with robust hierarchical structure for high-performance lithium-ion batteries J. Mater. Chem. A 6 2974-2983 [11] Jin W W, Zou J Z, Zeng S Z, Inguva S, Xu G Z, Li X H, Peng M and Zeng X R 2019 Tailoring the structure of clew-like carbon skeleton with 2D Co-MOF for advanced Li-S cells Applied Surface Science $469404-413$

[12] Ao X, Sun H Y, Wang C D, Li J G, Ruan Y J, Li B Z, Wu Q H, Li Y, Jiang J J, Yang, Y G and Mai L Q 2018 In situ nitrogen-doped helical mesoporous carbonaceous nanotubes for superior-high lithium anodic performance Carbon 130 599-606

[13] Liu Y, Xu J and Liu S C 2016 Porous carbon nanosheets derived from Al-based MOFs for supercapacitors Microporous and Mesoporous Materials 236 94-99

[14] Liu Y, Liu S C and Yue Z F 2015 Mesoporous alumina nanosheets and nanorolls derived from topologically identical Al-based MOFs RSC Adv 5 31742-31745

[15] Senkovska I, Hoffmann F, Froba M, Getzschmann J, Böhlmann W and Kaskel S 2009 New highly porous aluminium based metal-organic frameworks: $\mathrm{Al}(\mathrm{OH})(\mathrm{ndc})(\mathrm{ndc}=2,6$-naphthalene dicarboxylate) and $\mathrm{Al}(\mathrm{OH})(\mathrm{bpdc})$ (bpdc=4,40-biphenyl dicarboxylate) Microporous and Mesoporous Materials 122 93-98

[16] Su J, Kapaca E, Liu L F, Georgieva V, Wan W, Sun J L, Valtchev V, Hovmöller S and Zou X D 2014 Structure analysis of zeolites by rotation electron diffraction (RED) Microporous and Mesoporous Materials 189 115-125

[17] Ellis J E, Zeng Z D, Hwang S I, Li S, Luo T Y, Burkert S C, White D L, Rosi N L, Gassensmith J J and Star A 2019 Growth of ZIF-8 on molecularly ordered 2-methylimidazole/single-walled carbon nanotubes to form highly porous, electrically conductive composites Chem. Sci 10 737-742 
[18] Sarawade P, Tan H, Anjum D, Cha D and Polshettiwar V 2014 Size- and Shape-Controlled Synthesis of Hexagonal Bipyramidal Crystals and Hollow Self-Assembled Al-MOF Spheres ChemSusChem 7 529-535

[19] Hu M, Reboul J, Furukawa S, Torad N L, Ji Q M, Srinivasu P, Ariga K, Kitagawa S and Yamauchi Y 2012 Direct Carbonization of Al-Based Porous coordination polymer for synthesis of nanoporous carbon J. Am. Chem. Soc 134 2864-2867

[20] Fanjul F, Granda M, Santamaria R and Menendez R 2002 On the chemistry of the oxidative stabilization and carbonization of carbonaceous mesophase Fuel 81 2061-2070

[21] Li X L, Zhang B Y, Fang Y H, Sun W J, Qi Z Y, Pei Y C, Qi S Y, Yuan P Y, Luan X C, Goh T W and Huang WY 2017 Metal-Organic-Framework-Derived Carbons: Applications as Solid-Base Catalyst and Support for Pd Nanoparticles in Tandem Catalysis Chem. Eur. J 23 4266-4270 [22] Karacan I and Erzurumluoğlu L 2015 The effect of carbonization temperature on the structure and properties of carbon fibers prepared from poly(m-phenylene Isophthalamide) Precursor Fibers and Polymers 16 1629-1645

[23] Punckt C, Muckel F, Wolff S, Aksay I A, Chavarin C A, Bacher G and Mertin W G 2013 the effect of degree of reduction on the electrical properties of functionalized graphene sheets Appl. Phys., Lett 102023114

[24] Ye J, Zang J, Tian Z, Zheng M and Dong Q 2016 Sulfur and nitrogen co-doped hollow carbon spheres for sodium-ion batteries/with superior cyclic and rate performance J. Mater. Chem. A 4 $13223-13227$

[25] Shi R Y, Han C P, Li H F, Xu L, Zhang T F, Li J Q, Lin Z Q, Wong C P, Kang F Y and Li B H 2018 NaCl-templated synthesis of hierarchical porous carbon with extremely large specific surface 
area and improved graphitization degree for high energy density lithium ion capacitors J. Mater. Chem. A. $617057-17066$

[26] Lu M J, Yu W H, Shi J, Liu W, Chen S G, Wang X and Wang H L 2017 Self-doped carbon architectures with heteroatoms containing nitrogen, oxygen and sulfur as high-performance anodes for lithium- and sodium-ion batteries Electrochimica Acta 251 396-406 [27] Liu R P, Shen C, Dong Y, Qin J L, Wang Q, Iocozzia J, Zhao S Q, Yuan K J, Han C P, Li B H and Lin Z Q 2018 Sandwich-like CNTs/Si/C nanotubes as high performance anode materials for lithium-ion batteries J. Mater. Chem. A 6 14797-14804

[28] Li X W, Qiao L, Li D, Wang X H, Xie W H and He D Y 2013 Three-dimensional network structured alpha- $\mathrm{Fe}_{2} \mathrm{O}_{3}$ made from a stainless steel plate as a high-performance electrode for lithium ion batteries J.Mater. Chem.A 1 6400-6406

[29] Chen M, Yu C, Liu S H, Fan X M, Zhao C T, Zhang X and Qiu J S 2015 Micro-sized porous carbon spheres with ultra-high rate capability for lithiumstorage Nanoscale 7 1791-1795 [30] Fang Y, Lv Y Y, Che R C, Wu H Y, Zhang X H, Gu D, Zheng G F and Zhao D Y 2013 Two-dimensional mesoporous carbon nanosheets and their derived grapheme nanosheets: synthesis and efficient lithium ion storage J. Am. Chem. Soc 135 1524-1530 [31] Wang D, Wang Z Y, Li Y, Dong K Z, Shao J H, Luo S H, Liu Y G and Qi X W 2019 In situ double-template fabrication of boron-doped 3D hierarchical porous carbon network as anode materials for Li- and Na-ion batteries Applied Surface Science 464 422-428

[32] Seidl L, Martens S, Ma J W, Stimming U and Schneider O 2016 In situ scanning tunneling microscopy studies of the SEI formation on graphite electrodes for $\mathrm{Li}^{+}$-ion batteries Nanoscale 8 14004-14014

[33] Matsumura Y, Wang S and Mondori J 1995 Mechanism leading to irreversible capacity loss in 
[34] Stevens D A and Dahn J R 2001 The mechanisms of lithium and sodium insertion in carbon materials J. Electrochem. Soc 148 A803-A811

[35] Zhang J, Liu X F, Wang J, Shi J L and Shi Z Q 2016 Different types of pre-lithiated hard carbon as negative electrode material for lithium-ion capacitors Electrochimica Acta 187 134-142

[36] Cao B, Liu H, Xu B, Lei Y, Chen X and Song H 2016 Mesoporous soft carbon as an anode material for sodium ion batteries with superior rate and cycling performance J. Mater. Chem A 4 $6472-6478$

[37] Li D, Zhang L, Chen H, Ding L X, Wang S, Wang H 2015 Nitrogen-doped bamboo-like carbon nanotubes: promising anode materials for sodium-ion batteries Chem. Commun 51 16045-16048 [38] Feng J M, Dong L, Li X F, Li D J, Lu P Y, Hou F, Liang J and Dou S X 2019 Hierarchically stacked reduced graphene oxide/carbon nanotubes for as high performance anode for sodium-ion batteries Electrochimica Acta 302 65-70 
2019-12-20

\section{Al-based MOF derived self-assembled carbon nanosheets as innovative anodes for Li-and Na-ion batteries}

Zeng, Xie-Rong

IOP

Zeng X, Jin W, Li H, et al., (2019) Al-based MOF derived self-assembled carbon nanosheets as innovative anodes for Li-and Na-ion batteries, Nanotechnology, Volume 31, Issue 15, 2020,

Article number 155602

https://doi.org/10.1088/1361-6528/ab647b

Downloaded from Cranfield Library Services E-Repository 